\title{
VIEWPOINT
}

\section{The pain is real but so is the progress}

\author{
N. B. HERSHFIELD, MD, FRCP(C), FACP
}

$\mathrm{T}$ HIS YEAR MARKED MY 20TH YEAR AS A PRACTISING gastroenterologist and I have become very philosophical. I believe it is important to reflect on one's experience from time to time - something we do too rarely in our busy lives.

My thoughts today concern that bugbear of all gastroenterologists, inflammatory bowel disease, especially Crohn's disease (which the Annals of Internal Medicine, for some obscure reason of their own, continually refer to as Crohn disease). As we all know, it was first characterized in 1932 and after over 50 years we still do not know what causes it or how to treat it effectively. I suppose that the academicians among you are assuredly as frustrated as we clinicians and for good reason. The patients are generally young, in their prime, their suffering is legion, sure to tug the strings of even the hardest heart. Many of them suffer incredible complications; emotional destruction as well as physical deformity. Their lives are excoriated, their future is very uncertain, many lose their jobs, their self esteem and frequently their spouses and loved ones. They also lose a considerable length of their respective guts!

The treatment itself can be destructive. Broken bones from corticosteroids, marrow suppression from salazopyrin and who knows what long term effects from immunosuppressive drugs. The surgical attack is fraught with complications.

Clinical Professor, Department of Medicine, University of Calgary, 711 South Tower, 3031 Hospital Drive NW, Calgary, Alberta T2N 2 T9
The Canadian Foundation for Ileitis and Colitis (CFIC) has a slogan - "The Pain is Real" implying what we doctors who deal with this condition know - that many of the patients are considered by some to be imagining their pain. The myth that patients with inflammatory bowel disease are somehow emotionally unstable, still permeates our profession from doctors to nurses and even some of the patients themselves. This attitude I believe was one of the main reasons why progress in the disorder was so slow.

It is easy to get depressed about inflammatory bowel disease, both the doctors and the patients are acutely aware of that. So while it is true that the pain is real, so is the progress, despite our relative lack of knowledge.

There is certainly better awareness of the disease by the medical profession and the lay public. The diagnosis, I am certain, is made much earlier than it was when I first started in practice, and this has led to increased pressure for research, both as to the cause of the disease and better forms of therapy.

The first patient that I saw with inflammatory bowel disease in Calgary was 47 years old. I have been seeing her regularly for the past 20 years. When I first saw her she had been complaining of various and sundry intestinal problems for about 10 years and was told that she had a 'nervous bowel'.

It was not a difficult diagnosis to make. I simply did a small bowel follow-through. She went on to have three surgical operations in the next 20 years as befits any self respecting patient with the disorder.

She came in to see me in the office the other day and told 
me how grateful she was that I had diagnosed her. I told her that I really did not do her any service as she has not been better since she had met me, in fact, she became a chronic patient. She is a very intelligent lady and she said, "you know, it was very important to have a label on my disorder. I was really getting very depressed because everyone was telling me I was crazy and I was imagining my problem. Although you did not make me better, I was able to cope more effectively with the fact that I had 'something' and was not a total lunatic". Although that is perhaps small compensation but I suppose it is important to be told that what you are suffering from is not 'all in the mind'. (We have enough of those in our practice!)

\section{BETTER AWARENESS; BETTER TREATMENT}

Increased awareness of the diseases had led to better training of our GI Fellows that follow us and also deeper understanding among the nursing profession who, after all, deal with these patients when they are in hospital for much longer periods than we do,

Certainly there is better treatment. Total parenteral nutrition has at least allowed some of those patients that had miles of bowel resected, to live a relatively normal life; although of course, they are still patients. The first patient treated by total parenteral nutrition in southern Alberta is now 11 years into her therapy, and has travelled all over the world with her central venous catheter (one of three that have been placed in her since she began). Prior to that she was neverable to go anywhere because she was continually having diarrhea and all the other sundry effects of her short gut syndrome.

Diagnostic technology has improved as well. Colonoscopy and the small bowel enema and radioisotope scans have allowed us to make the diagnosis much earlier and far more precisely. Whether or not this is going to change the natural history of the disease, is as yet unknown.

Our pathologists are far better at recognizing the changes from the little biopsies we send them and, in areas where the disease is very common, radiologists are constantly aware of the importance of careful study of the $\mathrm{x}$-rays.
I recall patients back in the 50 s who had ileostomies becoming virtual recluses and hermits because of the poor technology that was associated with the ileostomy and also the misunderstanding of the proper surgical creation of an ileostomy. Certainly that has improved. Today's appliances are excellent, and the ileostomates themselves are continually devising new and better ways of maintaining that equipment.

The emergence of the pouch operations has greatly improved the outlook for patients who require surgery. It is now far easier to suggest surgery in a patient with ulcerative colitis when we know that they will have continence and an intact anal sphincter mechanism. No longer do we have to subject them to long periods of drug treatment, some of them with devastating side effects before they finally agree to surgery.

The field of nutritional support with the elemental diet and nasogastric feeding, has also improved the well-being of these patients. It is now rare to see those Buchenwaldoid patients that used to grace our hospitals.

The awareness of the psychosocial effects of these devastating diseases has certainly improved primarily through the efforts of CFIC. It is my contention now that every patient with the diagnosis of inflammatory bowel disease, especially if you think it is going to take a 'malignant course', should be seen by a psychologist or psychiatrist or social worker very early in their disease as they have to be made pretty tough for the future onslaught they are going to suffer.

Obviously all is not roses but I do not think that there is any doubt that shortly, through the efforts of our basic scientists and researchers, another breakthrough will be made in the care and management of these patients. early in their disease as they have to be made pretty tough for the future onslaught they are going to suffer.

Obviously all is not roses but I do not think that there is any doubt that shortly, through the efforts of our basic scientists and researchers, another breakthrough will be made in the care and management of these patients.

Although the pain is real, I believe the progress is also real and all is not despair. 


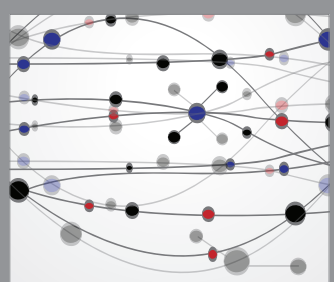

The Scientific World Journal
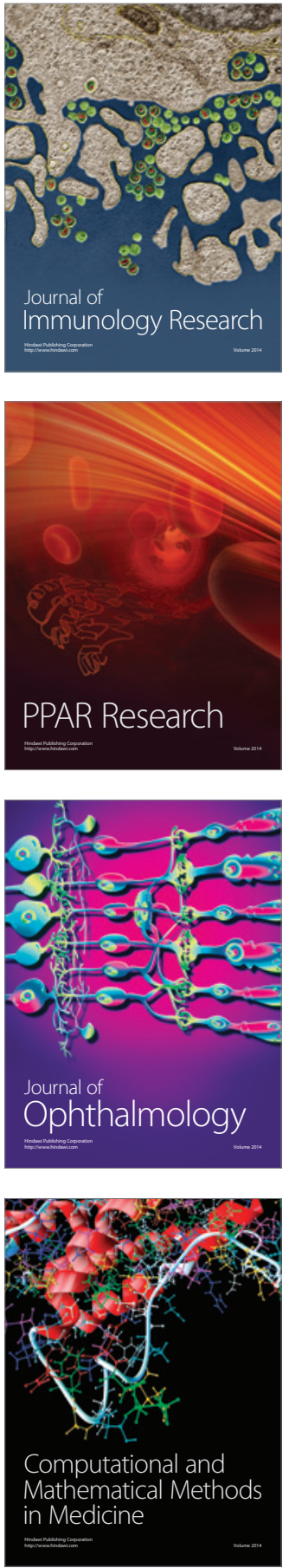

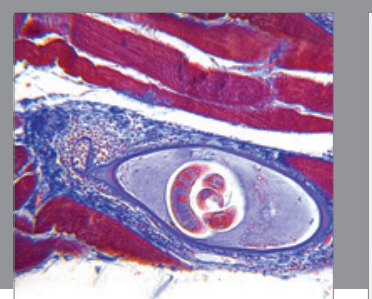

Gastroenterology Research and Practice

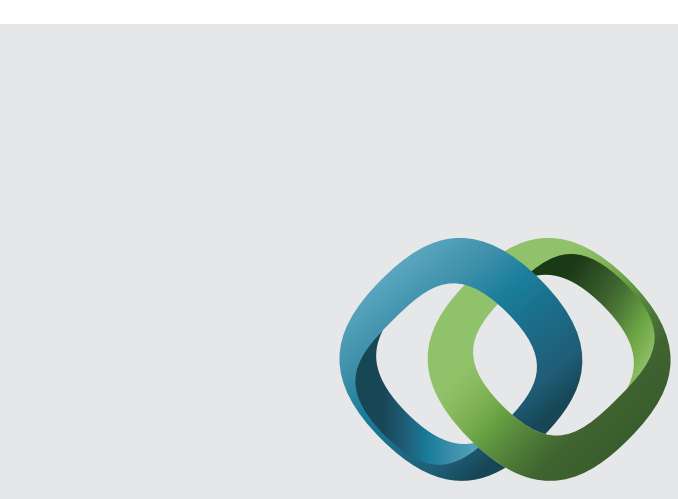

\section{Hindawi}

Submit your manuscripts at

http://www.hindawi.com
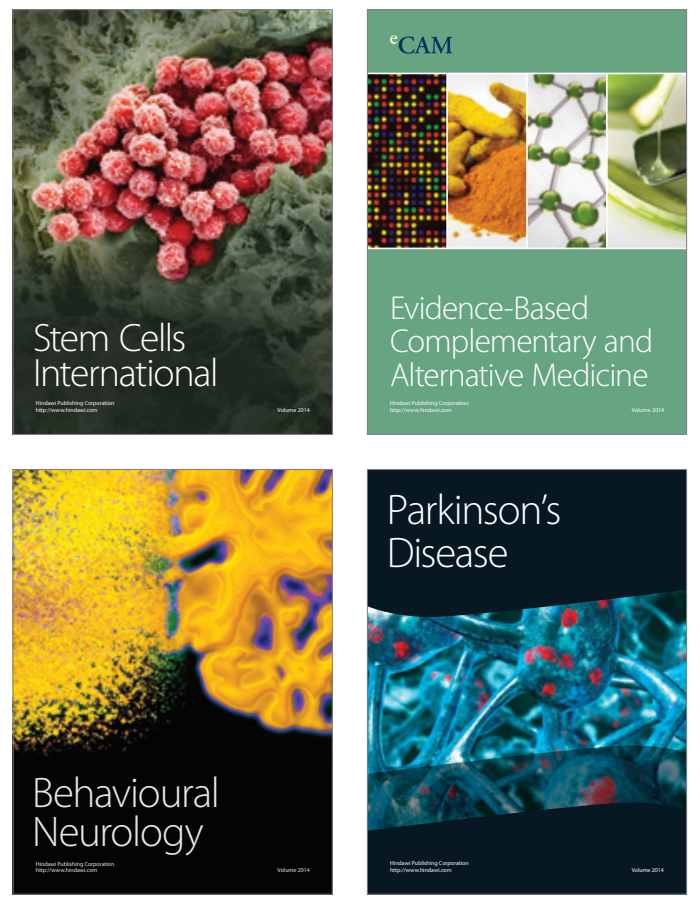
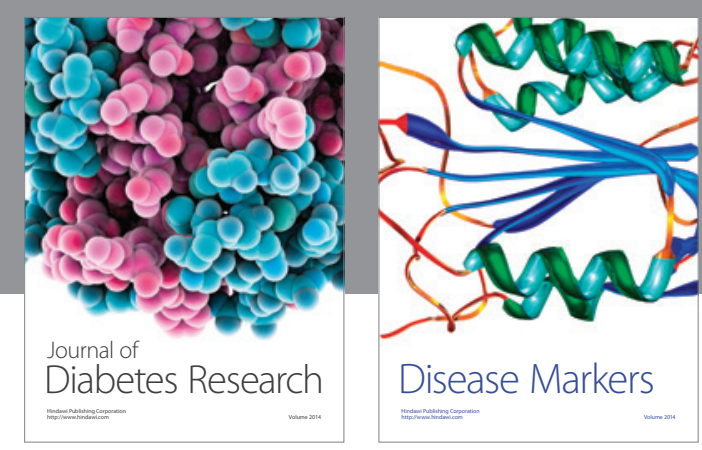

Disease Markers
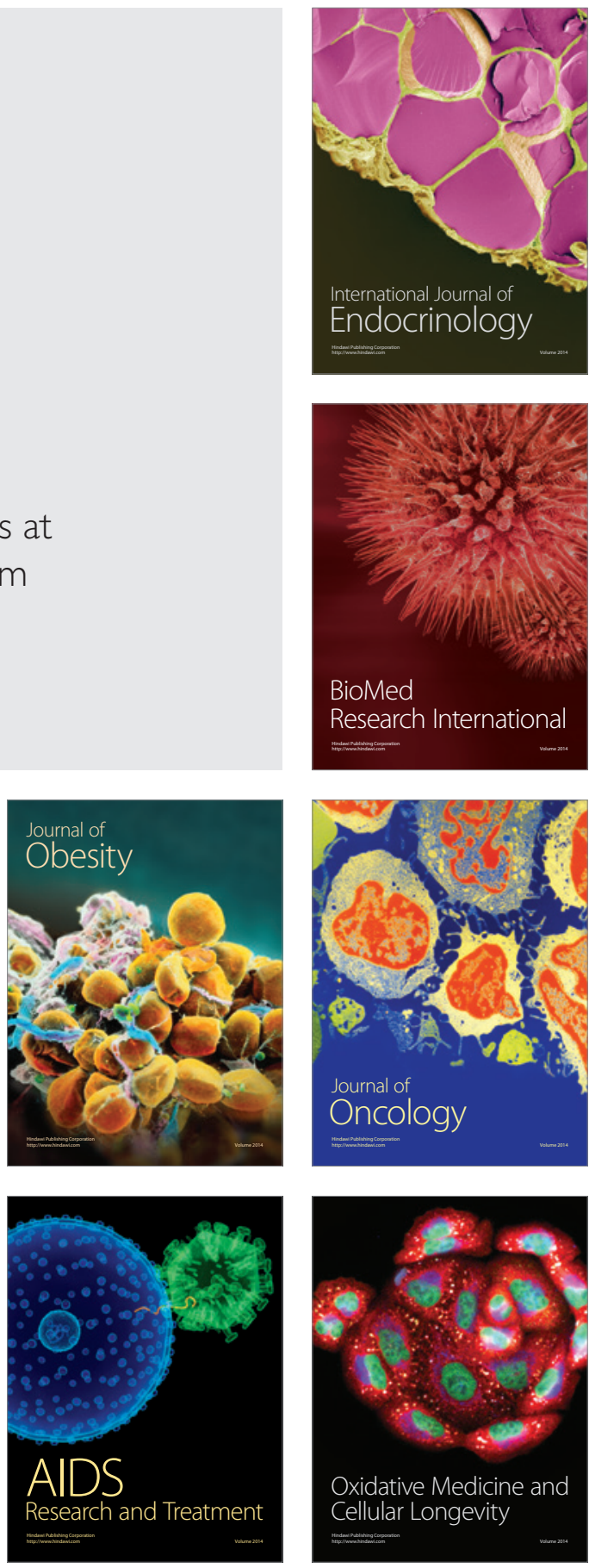